\title{
MODELAGEM CLIMÁTICA REGIONAL (DOWNSCALING) E APLICAÇÕES EM ENERGIA EÓLICA: VARIABILIDADE E MUDANÇAS CLIMÁTICAS
}

\author{
Francisca Dayane Carneiro Melo*1, Ruth P. S. Leão ${ }^{1}$, Alexandre Araújo Costa ${ }^{2}$, Danielle \\ Kely Saraiva de Lima ${ }^{1}$, Camylla Maria Narciso de Melo Chaves ${ }^{1}$ \\ ${ }^{1}$ Universidade Federal do Ceará (UFC) \\ ${ }^{2}$ Universidade Estadual do Ceará (UECE) \\ *dayane.fcm@gmail.com
}

\section{RESUMO}

Atualmente, os modelos atmosféricos de circulação geral (AGCMs) apresentam uma resolução espacial entre 100 e $200 \mathrm{~km}$ para previsões climáticas sazonais (e, eventualmente mais grosseira ainda quando se trata de estudos de mudanças climáticas). Para tomada de decisão ao nível regional/local, pelo estado ou pela sociedade civil, no entanto, há uma demanda por uma maior resolução nas previsões e cenários, já que a variabilidade espacial e temporal da precipitação associada com processos físicos não resolvidos em AGCMs (circulações atmosféricas de mesoescala) pode afetar de forma significativa determinada atividade econômica. $\mathrm{O}$ setor de energias renováveis, especialmente a energia eólica, cujo crescimento sobre o norte do Nordeste Brasileiro (NEB), especialmente sobre o Ceará, tem sido acentuado, também requer informação de alta resolução espacial para planejamento de suas ações na escala da variabilidade climática sazonal, bem como para avaliação dos potenciais impactos das mudanças climáticas antropogênicas sobre a disponibilidade dos recursos energéticos renováveis na região.

\section{INTRODUÇÃO}

$\mathrm{Na}$ medida em que a energia eólica passa a ser um componente significativo na matriz energética do Estado do Ceará, uma previsão climática sazonal dos recursos eólicos passa a ser importante para o planejamento energético e é de grande importância que, além de um sistema de previsão de vento em escala de tempo, o setor de energias alternativas sobre o Nordeste Brasileiro (NEB) seja subsidiado por contribuições que englobem também a escala de clima. Isto inclui tanto a previsão em escala sazonal quanto projeções de longo prazo face às mudanças climáticas, que permitem orientar as políticas para o setor energético investigando o impacto das mudanças climáticas sobre a disponibilidade do recurso eólico para a geração de energia elétrica.

\section{MATERIAIS E MÉTODOS}

A construção de uma plataforma de previsão sazonal de ventos e de geração de energia eólica tem como ponto de partida o sistema de previsão por downscaling já operacional na Fundação Cearense de Meteorologia e Recursos Hídricos (FUNCEME), por 
meio da utilização de modelos atmosféricos de área limitada (RSM - Regional Spectral Model), primeiro modelo implementado naquela instituição (Sun et al. 2005).

A FUNCEME, pioneira na comunidade meteorológica mundial no uso operacional da técnica do downscaling para previsão climática regional, estabeleceu um novo sistema operacional de previsão climática regional com dois modelos regionais sendo alimentados pelo modelo global ECHAM 4.5, e o RAMS (Regional Atmospheric Modeling System) com 10 membros sendo simulados para cada cenário de Temperatura da Superfície do Mar (TSM com anomalia persistida e TSM prevista)

\section{RESULTADOS E DISCUSSÃO}

O RAMS-ECHAM conseguiu representar a evolução esperada do ciclo anual da intensidade dos ventos no domínio do modelo, particularmente, a oscilação anual desta variável sobre o norte do NEB, com um mínimo durante a estação chuvosa e um máximo durante a estação seca.

O ciclo anual médio da intensidade do vento nos 46 anos de simulação sobre as regiões anteriormente definidas como norte, leste e sul do NEB é mostrado na Figura 1. Em todas as regiões, o pico da velocidade do vento ocorre no segundo semestre, acompanhando o deslocamento ao norte da AAS. O ciclo anual é particularmente intenso no norte do NEB, com valores variando de $4,1 \mathrm{~m} / \mathrm{s}$ em março a $7,5 \mathrm{~m} / \mathrm{s}$ em setembro. Vale ressaltar que os valores relativamente baixos de velocidade do vento para esta região estão associados à extensão da área considerada, que cobre vastas áreas do interior do continente, caracterizadas por ventos de menor intensidade. No leste do NEB, a intensidade média do vento, segundo o RAMS-ECHAM, varia de 5,6 m/s (marco) a 8,2 m/s (julho); no sul do NEB, de 4,5 m/s (marco) a 6,5 m/s (agosto).

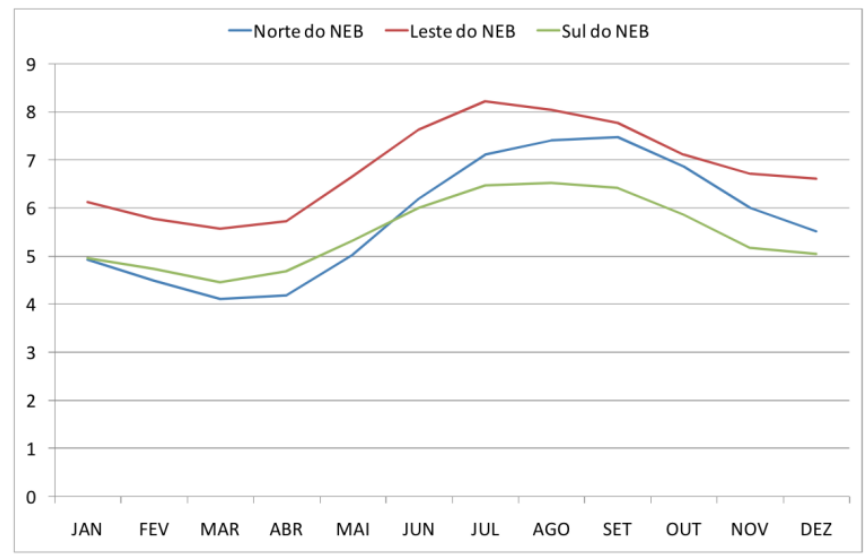

Figura 1 - Ciclo anual médio da velocidade do vento nas três regiões analisadas, obtido a partir dos 46 anos de simulação do RAMS/ECHAM

As três variáveis analisadas, relevantes para estudos de aproveitamento de fontes renováveis de energia, apresentam variabilidade interanual que está associada, em vários casos, ao estado das porções tropicais das bacias dos oceanos Pacífico e Atlântico. Por existir uma relação causal entre fração de cobertura de nuvens e radiação solar incidente à superfície (isto é, elevada nebulosidade implica em aumento do espalhamento e, portanto, 
redução do fluxo radiativo), a correlação entre estas variáveis é muito significativa em todas as regiões (e, evidentemente, negativa), chegando a valores de $-0,65$ (norte do NEB), -0,77 (leste do NEB) e -0,91 (sul do NEB). Por sua vez, a correlação entre vento e radiação, bem como a correlação entre vento e cobertura de nuvens só é relativamente elevada no norte do NEB $(0,45$ e $-0,57$, respectivamente), mas é menor tanto no leste $(-0,02$ e 0,13$)$ quanto no sul do NEB $(0,29$ e $-0,21)$.

\section{CONCLUSÕES}

Mesmo com uma resolução ainda inadequada para as aplicações em energias, os resultados do novo sistema de downscaling são promissores no sentido de que é viável produzir uma previsão sazonal para as variáveis a elas relacionadas.

\section{AGRADECIMENTOS}

A CAPES e FUNCAP pelo apoio financeiro e ao Mestrado Acadêmico em Ciências Físicas Aplicadas pelo suporte técnico.

\section{REFERÊNCIAS BIBLIOGRÁFICAS}

Sun, L., D.F. Moncunill, H. LI, A.D. Moura, F.A. Souza Filho, "Climate Downscaling over Nordeste, Brazil, Using the NCEP RSM97”, Journal of Climate, 18, 551-567, 2005. 